\title{
Biotin Transport in the Rat Central Nervous System
}

\author{
Warren Lo, ${ }^{1,2, *}$ Theresa KadleceK, ${ }^{1}$ and Seymour PACKMAN ${ }^{1, * *}$ \\ ${ }^{1}$ Division of Genetics, Department of Pediatrics, Box 0748, \\ University of California-San Francisco, \\ San Francisco, CA 94143, U.S.A. \\ ${ }^{2}$ Division of Pediatric Neurology, Departments of Neurology \\ and Pediatrics, University of California-San Francisco, \\ San Francisco, CA 94143, U.S.A.
}

(Received May 13, 1991)

\begin{abstract}
Summary Previous studies in the biotin-deficient rat have shown that brain biotin concentrations and the activity of biotin-dependent carboxylases are relatively preserved in the face of biotin starvation and systemic biotin deficiency. These data suggested the existence of a concentration mechanism for biotin in brain, and the present studies were undertaken to further characterize brain biotin transport. We presently show that rat cerebrospinal fluid biotin concentrations are 2.5 times higher than serum concentrations, consistent with the existence of a concentrative mechanism for biotin. Further, we demonstrate uptake of ${ }^{3} \mathrm{H}$-biotin into rat brain from blood at physiologic biotin concentrations, using single pass clearance measurements of a brain uptake index. The calculated brain uptake indices for biotin, and the inhibition kinetics, are consistent with the possible existence of a low affinity mediated uptake mechanism. The results have implications for the pathophysiology of human biotinresponsive multiple carboxylase deficiency.
\end{abstract}

Key Words biotin, brain uptake index, rat, carboxylase, transport, central nervous system

The biotin-responsive multiple carboxylase deficiencies are autosomal recessive inborn errors that present in the newborn period with congenital lactic acidosis, or later in infancy with a more variable and gradual clinical course (1). Although there is frequently clinical overlap among patients $(2,3)$, defective activity of holocarboxylase synthetase has generally been observed in the first category $(2,4)$, and significant reductions in biotinidase activity in the second (5). Neurologic findings in patients have included acute metabolic encephalopathy (6), seizures,

$*$ Present address: Department of Pediatrics, Ohio State University, Columbus, $\mathrm{OH}$ 43220, U.S.A.

** All correspondence should be addressed. 
developmental delay and intermittent cerebellar ataxia (7). The basis of the ataxia was elucidated by the brain histology of one untreated 3.5-year-old boy with biotinidase deficiency: there was cerebellar degeneration, with Purkinje cell and granular atrophy restricted to the superior vermis (7).

The biotin-deficient rat was developed as a system to study the pathophysiology of central nervous system disease in the carboxylase deficiencies. Initial work suggested distinct patterns of biotin metabolism in brain, as compared with systemic tissues. Specifically, we showed that cerebrum, brainstem and cerebellar pyruvate carboxylase [EC 6.4.1.1] activities were preferentially maintained in biotin-starved rats. Under conditions which reduced hepatic pyruvate carboxylase activities to $3 \%$ of control, that of cerebrum, brainstem and cerebellum remained at 53 to $71 \%$ of control (8). Our data, and those of others on pyruvate carboxylase $(9,10)$ and propionyl CoA carboxylase [EC 6.4.1.3] (9), were consistent with a relative retention of biotin in brains of biotin-deficient rats (11). In the present work, we ask whether there exists a concentrative mechanism for biotin in rat brain.

\section{METHODS}

$d$-Biotin and thiourea were purchased from the Sigma Corporation (St. Louis). Avidin was purchased from Vector Laboratories (Burlingame). $d$-(8,9$\left.{ }^{3} \mathrm{H}(\mathrm{N})\right)$ biotin $\left({ }^{3} \mathrm{H}\right.$-biotin, $\left.41.4 \mathrm{Ci} / \mathrm{mmol}\right),\left[{ }^{14} \mathrm{C}\right]$ thiourea $(50 \mathrm{mCi} / \mathrm{mmol})$ and $\left[{ }^{14} \mathrm{C}\right]$ phenylalanine $(510 \mathrm{mCi} / \mathrm{mmol})$ were purchased from the New England Nuclear Corporation (Boston). For ${ }^{3} \mathrm{H}$-biotin and $\left[{ }^{14} \mathrm{C}\right]$ thiourea the manufacturers' specifications of purity were confirmed in our laboratory. The single peaks of radioactivity for both thiourea and biotin comigrated with the authentic compounds on silica gel thin-layer chromatography. Further, $96.3 \%$ of the ${ }^{3} \mathrm{H}$-biotin remained bound to an avidin-Sepharose column when applied and washed with $0.01 \mathrm{M} \mathrm{Na}$ phosphate buffer, pH $7.0\left(0.029 \mathrm{nmol}{ }^{3} \mathrm{H}\right.$-biotin applied to $24 \mathrm{nmol}$ avidin $)$.

Biotin concentrations were measured by the method of Sanghvi et al. (12), in serum and cerebrospinal fluid of Sprague-Dawley rats maintained on conventional feeding schedules. Animals were used in experiments according to institutional review and approval.

Brain clearance of ${ }^{3} \mathrm{H}$-biotin was measured following rapid carotid injection, using the method of Oldendorf (13). Injectates containing radiolabeled test and reference compounds were prepared in Ringer's solution-HEPES buffer, pH 7.4 $(13,14)$. Concentrations of radiolabeled ${ }^{3} \mathrm{H}$-biotin and ${ }^{14} \mathrm{C}$-reference substances in the injectate were adjusted to achieve ratios of $10: 1$ as $\mu \mathrm{Ci}$ of ${ }^{3} \mathrm{H}: \mu \mathrm{Ci}$ of ${ }^{14} \mathrm{C}$, in order to facilitate dual label liquid scintillation counting. Midline neck incisions were made in $240-260 \mathrm{~g}$ anesthetized (intraperitoneal pentobarbital, $50 \mathrm{mg} / \mathrm{kg}$ ) male Sprague-Dawley rats, and the right common carotid artery was exposed and cannulated with a bent 27 gauge needle. Decapitation was performed 5-7s after rapid injection of $0.21-0.28 \mathrm{ml}$ of injectate. The right cerebral hemisphere was removed, placed in a $2.5 \mathrm{ml}$ syringe and duplicate aliquots of (approximately) 0.25 
Table 1. Brain uptake of ${ }^{3} \mathrm{H}$-biotin.

\begin{tabular}{ccc}
\hline $\begin{array}{c}\text { Biotin concentration } \\
\text { of injectate }\end{array}$ & $\begin{array}{c}\text { BUI }^{1}(\%) \\
{\left[{ }^{14} \mathrm{C}\right] \text { Thiourea reference }}\end{array}$ & $\begin{array}{c}\text { BUI (\%) } \\
{\left[{ }^{14} \mathrm{C}\right] \text { Phenylalanine reference }}\end{array}$ \\
\hline $2.24 \mathrm{nM}$ & $4.0 \pm 0.44(4)^{2}$ & - \\
$4.12 \mathrm{nM}$ & $4.1 \pm 0.88(5)$ & $5.1 \pm 2.2(4)$ \\
$409 \mathrm{nM}$ & $5.7 \pm 0.52(3)$ & - \\
$4,093 \mathrm{nM}$ & $5.7 \pm 1.6(2)$ & - \\
\hline
\end{tabular}

${ }^{1}$ Experimental procedures as in Materials AND METHODS. BUI as a percent of clearance by brain was calculated $(13)$ as (brain ${ }^{3} \mathrm{H} /$ brain ${ }^{14} \mathrm{C}$ )/(injected ${ }^{3} \mathrm{H} /$ injected $\left.{ }^{14} \mathrm{C}\right) \times 100 \times K$. For $\left[{ }^{14} \mathrm{C}\right]$ thiourea, $K=0.045(13)$; for $\left[{ }^{14} \mathrm{C}\right]$ phenylalanine, $K=0.55$ $(13,15) .{ }^{2}$ Values are in percent, as mean \pm standard deviation (No. of independently studied rats). Each rat brain was counted in duplicate.

g of brain were each extruded through a 20 gauge needle directly into scintillation vials. Following solubilization in $1.5 \mathrm{ml}$ NCS (Amersham), the duplicate samples were counted in a toluene-based fluor (after $24 \mathrm{~h}$ in the dark) in a Beckman LS7000 liquid scintillation counter, with an automatic quench compensation program. An instrument program for the simultaneous counting of ${ }^{3} \mathrm{H}$ and ${ }^{14} \mathrm{C}$ was used. An aliquot of the injection mixture was similarly counted.

\section{RESULTS}

We first compared cerebrospinal fluid and serum biotin concentrations under homeostatic conditions. Serum biotin concentration was $19.9 \pm 5.45 \mathrm{~nm}$ (mean \pm $\mathrm{SD}$, range $13.9-29.5 \mathrm{nM}$, six independently measured rats). Including these same rats, cerebrospinal fluid concentration was $49 \pm 15.1 \mathrm{nM}$ (mean $\pm \mathrm{SD}$, range $35.8^{-}$ $65.6 \mathrm{nM}$, three separate determinations, with two of the determinations in pooled samples from 3-5 rats).

We next asked whether uptake of biotin into brain could be demonstrated in vivo. Brain uptake of ${ }^{3} \mathrm{H}$-biotin was measured at injectate biotin concentrations that were $1 / 9$ and $1 / 4$ homeostatic serum biotin levels (as determined above), using $\left[{ }^{14} \mathrm{C}\right]$ thiourea as a diffusible reference (Table 1). The mean brain uptake indices (BUI) were 4.0 and $4.1 \%$ respectively, comparable to the $4.5 \%$ (13) of the low-clearance thiourea reference. When $\left[{ }^{14} \mathrm{C}\right]$ phenylalanine (clearance $55 \%(13,15)$ ) was used as a high-clearance reference, a similar BUI, 5.5\%, was obtained.

No self-inhibition was demonstrated by the addition of unlabeled biotin to the injectate. The BUI (5.7\%, Table 1) was not reduced when the injectate contained biotin concentrations that were 20 and 206 times higher than homeostatic serum concentrations.

\section{DISCUSSION}

Studies in the biotin-deficient rat have shown that brain biotin concentrations 
(11), as well as the activity of biotin-dependent carboxylases (8-10), are relatively preserved in the face of biotin starvation and systemic biotin deficiency. Explanations for this finding include the possibility of a slower rate of carboxylase turnover in brain, or a reduced release of biotin from brain. We herein ask whether a concentrative system for biotin uptake exists in brain, to account for the biotin retention and carboxylase activity preservation.

We first asked whether cerebrospinal fluid biotin concentrations were higher than serum levels. Under homeostatic conditions, mean cerebrospinal fluid biotin concentration was 2.5 times higher than that in serum. This differential is similar to that observed for vitamins - such as ascorbate-for which central nervous system saturable transport processes have been documented $(16,17)$. The cerebrospinal fluid/serum ratio itself, however, does not distinguish between a mediated transport mechanism for uptake or biotin retention at the level of biotin exit.

We next demonstrated entry of biotin into rat brain from blood. The method $(13-15)$ is designed to measure single pass clearance by brain of a radiolabeled substance following rapid carotid injection, thereby focusing on blood brain barrier transport of the labeled compound apart from other factors affecting brain accumulation. Comparison of brain biotin uptake with that of a radiolabeled reference substance whose clearance is known, and whose clearance is similar to that of biotin, permits the calculation of a percent extraction, or brain uptake index (BUI) for biotin (13).

We determined that the BUI for biotin was $4 \%$, a value similar to the BUI for thiourea, a low-uptake compound used as the reference label (13). A similar BUI for biotin was obtained using an intermediate uptake reference, phenylalanine (13, 15). The results demonstrate entry of biotin with low clearance into rat brain at homeostatic biotin concentrations. The brain biotin uptake was not inhibited by the addition of unlabeled biotin to the injectate, over a range of concentrations up to $4.1 \mu \mathrm{M}$ (206 times homeostatic serum concentrations). The absence of selfinhibition at the concentrations used herein is consistent with the proposal in related studies (18) of a mediated transport system with a half-saturating concentration of approximately $100 \mu \mathrm{M}, 5,000$ times the mean serum biotin concentration. The physiologic significance of such mediation under homeostatic conditions is not clear.

The present and related data (18), take together, suggest that the facilitation of biotin concentration in brain in biotin-deficient states is more likely to reside at the level of biotin retention or exit, rather than biotin uptake. These data extend previous observations in experimental systems $(8-11)$, and can be related to clinical observations in the biotin-responsive multiple carboxylase deficiencies. In most such infants and children, biotin supplementation in pharmacologic doses leads to the reversal of neurologic and other symptomatology and even of apparent delays in developmental progress $(1,6,19,20)$. From the experimental data and clinical observations, it can be inferred that the production of irreversible cerebellar and other central neurologic symptoms requires prolonged absolute or relative biotin 
deprivation. The continued study of brain transport in experimental systems should be directly relevant to a more complete understanding of the pathophysiology of the carboxylase deficiencies, with greater accuracy in prognosis and refinements in therapy.

We thank Ms. Cotys Winston and Ms. Diana Voigts for their able editorial assitance in the preparation of the manuscript. This work was supported by USPHS NIH Grant No. AM 31366 and a grant from the March of Dimes Birth Defects Foundation.

\section{REFERENCES}

1) Sweetman, L., and Nyhan, W. (1986): Inheritable biotin-treatable disorders and associated phenomena. Annu. Rev. Nutr., 6, 317-343.

2) Sherwood, W., Saunders, M., Robinson, B., Brewster, T., and Gravel, R. (1982): Lactic acidosis in biotin-responsive multiple carboxylase deficiency caused by holocarboxylase synthetase deficiency of early and late onset. J. Pediatr., 101, 546-550.

3) Packman, S., Caswell, N., Gonzalez-Rios, M. C., Kadlecek, T., Cann, H., Rassin, D., and McKay, C. (1984): Acetyl CoA carboxylase in cultured fibroblasts: Differential biotin dependence in the two types of biotin-responsive multiple carboxylase deficiency. Am. J. Hum. Genet., 36, 80-92.

4) Burri, B., Sweetman, L., and Nyhan, W. (1981): Mutant holocarboxylase synthetase: Evidence for the enzyme defect in early infantile biotin-responsive multiple carboxylase deficiency. J. Clin. Invest., 68, 1491-1495.

5) Wolf, B., Grier, R., Allen, R., Goodman, S., and Kien, C. (1983): Biotinidase deficiency: The enzymatic defect in late-onset multiple carboxylase deficiency. Clin. Chim. Acta, 131, 273-281.

6) Packman, S., Sweetman, L., Baker, H., and Wall, S. (1981): The neonatal form of biotin-responsive multiple carboxylase deficiency. J. Pediatr., 99, 418-420.

7) Sander, J., Malamud, N., Cowan, M., Packman, S., Ammann, A., and Wara, D. (1980): Intermittent ataxia, organic aciduria and immunodeficiency: A vitamin responsive disorder. Ann. Neurol., 8, 544-547.

8) Sander, J., Packman, S., and Townsend, J. (1982): Brain pyruvate carboxylase and the pathophysiology of biotin dependent diseases. Neurology, 32, 878-880.

9) Chiang, G., and Mistry, S. (1974): Activities of pyruvate carboxylase and propionyl CoA carboxylase in rat tissues during biotin deficiency and restoration of the activities after biotin administration. Proc. Soc. Exp. Biol. Med., 146, 21-24.

10) Schrijver, J., Dias, T., and Hommes, F. (1979): Some biochemical observations on biotin deficiency in the rat as a model for human pyruvate carboxylase deficiency. Nutr. Metab., 23, 179-191.

11) Bhagavan, H., and Coursin, D. (1970): Depletion of biotin from brain and liver in biotin deficiency. J. Neurochem., 17, 289.

12) Sanghvi, R., Lemons, R., Baker, H., and Thoene, J. (1982): A simple method for determination of plasma and urinary biotin. Clin. Chim. Acta, 124, 85-92.

13) Oldendorf, W. (1981): Clearance of radiolabeled substances by brain after arterial injection using a diffusible internal standard. Res. Methods Neurochem., 5, 91-112.

14) Oldendorf, W., and Szabo, J. (1976): Amino acid assignment to one of three blood- 
brain barrier amino acid carriers. Am. J. Physiol., 230, 94-98.

15) Oldendorf, W. (1971): Brain uptake of radiolabeled amino acids, amines, and hexoses after arterial injection. Am. J. Physiol., 221, 1629-1639.

16) Spector, R. (1977): Vitamin homeostasis in the central nervous systems. N. Engl. J. Med., 296, 1393-1398.

17) Spector, R. (1979): Development of the vitamin transport systems in choroid plexus and brain. J. Neurochem., 33, 1317-1319.

18) Spector, R., and Mock, D. (1987): Biotin transport through the blood-brain barrier. J. Neurochem., 48, 400-404.

19) Cowan, M., Wara, D., Packman, S., Ammann, A., Yoshino, M., Sweetman, L., and Nyhan, W. (1979): Multiple biotin dependent carboxylase deficiencies associated with defects in T and B cell immunity. Lancet, 2, 115-118.

20) Packman, S., Sweetman, L., Yoshino, M., Baker, H., and Cowan, M. (1981): Biotin responsive multiple carboxylase deficiency of infantile onset. J. Pediatr., 99, 421-423. 